\title{
Article \\ Effect of Selected Trichoderma Strains and Metabolites on Olive Drupes
}

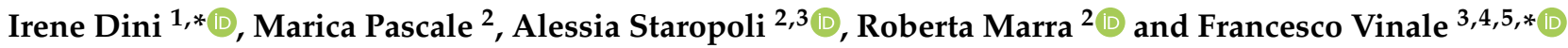 \\ 1 Department of Pharmacy, University of Naples Federico II, Via Domenico Montesano 49, \\ Portici, 80131 Naples, Italy \\ 2 Department of Agricultural Sciences, University of Naples Federico II, Portici, 80055 Naples, Italy; \\ marica.pascale@unina.it (M.P.); alessia.staropoli@unina.it (A.S.); robmarra@unina.it (R.M.) \\ 3 Institute for Sustainable Plant Protection, National Research Council, Portici, 80055 Naples, Italy \\ 4 Department of Veterinary Medicine and Animal Productions, University of Naples Federico II, \\ Portici, 80138 Naples, Italy \\ 5 BAT Center-Interuniversity Center for Studies on Bioinspired Agro-Environmental Technology, \\ University of Naples Federico II, Portici, 80055 Naples, Italy \\ * Correspondence: irdini@unina.it (I.D.); frvinale@unina.it (F.V.)
}

check for

updates

Citation: Dini, I.; Pascale, M.; Staropoli, A.; Marra, R.; Vinale, F. Effect of Selected Trichoderma Strains and Metabolites on Olive Drupes. Appl. Sci. 2021, 11, 8710. https:// doi.org/10.3390/app11188710

Academic Editors:

Raúl Rivas-González,

Esther Menéndez and José

David Flores-Félix

Received: 30 August 2021

Accepted: 17 September 2021

Published: 18 September 2021

Publisher's Note: MDPI stays neutral with regard to jurisdictional claims in published maps and institutional affiliations.

Copyright: (c) 2021 by the authors. Licensee MDPI, Basel, Switzerland. This article is an open access article distributed under the terms and conditions of the Creative Commons Attribution (CC BY) license (https:// creativecommons.org/licenses/by/ $4.0 /)$.

\begin{abstract}
Beneficial fungal strains of the genus Trichoderma are used as biofungicides and plant growth promoters. Trichoderma strains promote the activation of plant defense mechanisms of action, including the production of phenolic metabolites. In this work, we analyzed the effects of selected Trichoderma strains (T. asperellum KV906, T. virens GV41, and T. harzianum strains TH1, M10, and T22) and their metabolites (harzianic acid and 6-pentyl- $\alpha$-pyrone) on drupes of young olive trees (4-year-old) cv. Carolea. This study used the untargeted analysis of drupe metabolome, carried out by LC-MS Q-TOF, to evaluate the phenolics profiles and target metabolomics approach to detect oleuropein and luteolin. The untargeted approach showed significant differences in the number and type of phenolic compounds in olive drupes after Trichoderma applications (by root dipping and drench soil irrigation method) compared to control. The levels of oleuropein (secoiridoid) and luteolin (flavonoid) varied according to the strain or metabolite applied, and in some cases, were less abundant in treated plants than in the control. In general, flavonoids' levels were influenced more than secoiridoid production. The dissimilar aptitudes of the biological treatments could depend on the selective competence to cooperate with the enzymes involved in producing the secondary metabolites to defend plants by environmental stresses. Our results suggest that using selected fungi of the genus Trichoderma and their metabolites could contribute to selecting the nutraceutical properties of the olive drupe. The use of the metabolites would bring further advantages linked to the dosage in culture and storage.
\end{abstract}

Keywords: secondary metabolites; phenolic compounds; LC-MS Q-TOF; Olea europaea; Trichoderma; metabolomics

\section{Introduction}

Since ancient times olive trees (Olea europaea L.) have been cultivated throughout the Mediterranean area for their fruits and oil production. Each country has its local cultivars because the human selection and pedoclimatic conditions have resulted in genetic variations [1-4]. In Italy, many trees sprout spontaneously, and oil and table cultivars are grown mainly in Calabria, Apulia, Sicily, and Campania, where centuries-old trees and archaeological finds document their presence from old times [5]. Extravirgin olive oil (EVOO) is obtained from crushing the olive drupe and separating olive oil by pressure, centrifugation, and percolation (selective filtration process) [6]. EVOO is present in all variants of the Mediterranean diet. The latter is a healthy diet adopted by the Italian and Greek population in the 1960s [7], reducing the risk of cardiovascular disease, cancer, type 2 diabetes, and 
cognitive disorders [8]. It is characterized by high consumption of vegetables, fruit, salads, bread, whole grains, legumes/beans, nuts, seeds, moderate use of wine, and EVOO as the primary source of fat [8]. The EVOO has protective effects on human health due to the high content of monounsaturated fatty acids (MUFAs) and secondary bioactive molecules, including phenolic compounds, tocopherols, phytosterols, and carotenoids [9]. The phenolic compounds in EVOO range from 50 to $800 \mathrm{mg} / \mathrm{kg}[10,11]$. They consist of phenolic alcohols (e.g., tyrosol and hydroxytyrosol), phenolic acids (e.g., vanillic, caffeic, coumaric, protocatechuic, ferulic, and p-hydroxybenzoic), flavones (e.g., apigenin, apigenin-7-O-glucoside, luteolin, luteolin-7-O-glucoside), lignans (e.g., pinoresinol and acetoxypinoresinol), and secoiridoids (e.g., oleacein, oleuropein, oleocanthal, and p-HPEA-EA) [12] responsible for EVOO bitterness, pungency, fragrance, and antioxidative properties [13]. Fruit's maturation, cultivar varieties, pedoclimate condition [14], and the type of oil extraction processes affect the phenolic quality and concentration [15]. The oleuropein, tyrosol, and hydroxytyrosol (the main phenolic compounds in EVOO) [12] have antioxidant, anti-inflammatory, immunomodulatory, and neuroprotective activities [16]. The EVOO's polyphenols protect blood lipids against oxidative stress $[17,18]$. Therefore, the EVOO's phenolics are used in supplements for the prevention of chronic degenerative diseases such as cardiovascular diseases and cancer [19], in antiaging cosmetics [20,21], in the food industry as flavorings or preservers [22-24], and in functional foods preparations [25,26]. Olive plants make the phenolics in response to abiotic stress and pathogen attack [27-32]. Dini et al. in 2020 and 2021 investigated the effects of some Trichoderma strain applied to olive trees to evaluate a selective phenols production [33,34]. Nowadays, fungi belonging to the genus Trichoderma are commonly used in agriculture as biocontrol agents (they inhibit soils and air diseases) and plant growth promoters $[35,36]$. They also enhance the abiotic stress tolerance (e.g., salinity, drought), yields production, nutritional uptake, leaf area, root system growth, and activate protective mechanisms against oxidative injury [37,38]. Some Trichoderma strains produce secondary metabolites such as 6-pentyl-a-pyrone (volatile antibiotics), heptelidic acid, and peptaibols to help in metal transport, symbiosis, differentiation, and competition with another organism [39,40], and phenols against oxidative damage [41-43]. Phenols decrease cardiovascular pathologies, hypoglycemia, hypotension, and hypocholesterolemia and prevent angiogenesis, inflammation [44], and cancer [45].

In the present work, we report the effect of selected Trichoderma strains (e.g., T. asperellum KV906, T. harzianum strains TH1, M10, and T22; and T. virens GV41) and their metabolites (e.g., harzianic acid (HA), and 6-pentyl- $\alpha$-pyrone -(6PP)) upon in vivo application, on weight and phenol metabolites of the olive drupes in consideration of the commodity and nutraceutical importance of their potential effects.

\section{Materials and Methods}

\subsection{Microbial Strains}

Five Trichoderma strains (T. asperellum strain KV906, T. harzianum strains TH1, M10, and T22; and T. virens strain GV41) were used in this work. Strains were provided by Department of Agricultural Sciences of the University of Naples Federico II, after cultivation on previously described conditions [46].

A hemocytometer (Neubauer-improved, BRAND GMBH + CO KG, Wertheim, Germany) was used to establish the concentration of the spore suspensions.

\subsection{Trichoderma Bioactive Metabolites}

We used 6PP and HA in this work. The former was extracted from T. atroviride strain P1 [47] and the latter from T. harzianum strain M10 [48]. Metabolite solutions used for treatments were obtained by resuspending $\mathrm{HA}$ and $6 \mathrm{PP}$ in distilled water and ethyl acetate $0.01 \%(v / v)$ to facilitate the process. Once a clear solution was made, ethyl acetate was evaporated under nitrogen flow. 


\subsection{Plant Material}

Four-year-old olive trees (Olea europaea L cv. Carolea.) were used for experimental purposes. The plants were grown into plastic pots ( $50 \mathrm{~cm}$ diameter $\times 40 \mathrm{~cm}$ high) located in a field at the University of Naples Federico II-Department of Agricultural Sciences (Portici, Italy). Each pot contained one plant and $50 \mathrm{~L}$ of universal soil (granulated pumice, peat, and coconut fiber). Once a week, the plants were watered to field capacity. No nutrients were added.

\subsection{Experimental Design}

Eight treatments were performed (including water control), using five Trichoderma strains and two metabolites. The field trial was performed in a randomized block design. Trichoderma metabolite solutions $\left(1 \times 10^{-6} \mathrm{M}\right)$, or spore suspensions $\left(1 \times 10^{6} \mathrm{sp} \mathrm{mL}^{-1}\right)$ were inoculated through root system exposure at the time of transplant $\left(10 \mathrm{~min}, 1 \mathrm{~L} \mathrm{plant}^{-\mathrm{t}}\right)$ by root dip, and every 30 days $\left(400 \mathrm{~mL} \mathrm{plant}^{-1}\right.$ ) by soil irrigation (six applications in total). Each treatment was performed on 15 plants (five plants in each replicate and three biological replicates per treatment). Drupes were collected and weighed with an electronic digital scale (Precisa Instruments AG, model XB220A, Dietikon, Switzerland). Finally, drupes samples were stored at $-80{ }^{\circ} \mathrm{C}$ until extraction of metabolites.

\subsection{Chemicals}

Solvents (methanol, water, formic acid, acetonitrile) were purchased from SigmaAldrich (Sigma-Aldrich, St. Louis, MO, USA). ESI-TOF tune mix was bought from Agilent Technologies (Agilent Technologies, Santa Clara, CA, USA).

\subsection{Olive Metabolites Extraction}

Talhaoui et al. method [49], with some modifications, was used to extract the phenolic compounds. Briefly, drupes were freeze-dried and crushed. $200 \mathrm{mg}$ of powder were extracted twice in an ultrasonic bath for $10 \mathrm{~min}$ (Model $6.51200 \mathrm{H}$, Dakshin, India), using $5 \mathrm{~mL}$ of a solution of methanol/water $(50 / 50, v / v)$ and then centrifuged (Hettich GmbH and Co., Tuttlingen, Germany) at $4000 \mathrm{rpm}, 4{ }^{\circ} \mathrm{C}$ for $10 \mathrm{~min}$. The supernatants were collected, dried in a speed-vac (Savant SpeedVac, Thermo Fisher Scientific, Waltham, MA, USA) and dissolved in $2 \mathrm{~mL}$ of a solution of methanol/water $(50 / 50, v / v)$. Finally, the extracts obtained were filtered (Millipore $0.45 \mu \mathrm{m}$ ) and stored in the dark (at $-80{ }^{\circ} \mathrm{C}$ ) until use.

\subsection{Phenolics' Isolation, Identification, and Quantification}

\subsubsection{Metabolites' Analysis}

The analysis of metabolites was performed on an Agilent HP 1260 Infinity Series liquid chromatograph (Agilent Technologies, Santa Clara, CA, USA) equipped with a DAD system (Agilent Technologies, Santa Clara, CA, USA) and a Q-TOF mass spectrometer model G6540B (Agilent Technologies, Santa Clara, CA, USA).

\section{Chromatographic Conditions}

An InfinityLab Poroshell 120 EC-C18 column $(2.1 \mathrm{~mm} \times 100 \mathrm{~mm}, 2.7 \mu \mathrm{m})$ (Agilent Technologies, Santa Clara, CA, USA), at controlled temperature $\left(25^{\circ} \mathrm{C}\right)$ was used as stationary phase. Two eluents, phase A $(0.1 \%(v / v)$ formic acid in water) and phase B $(0.1 \%$ $(v / v)$ formic acid in acetonitrile), were employed as mobile phase. The gradient was set as follows: $0 \mathrm{~min}, 95 \% \mathrm{~A} ; 4 \mathrm{~min}, 91 \% \mathrm{~A} ; 7 \mathrm{~min}, 88 \% \mathrm{~A} ; 8 \mathrm{~min}, 85 \% \mathrm{~A} ; 9 \mathrm{~min}, 84 \% \mathrm{~A} ; 14 \mathrm{~min}$, $80 \%$ A; $15 \min , 78 \%$ A; $18 \min , 72 \%$ A; $19 \min , 70 \%$ A; $20 \min , 69 \%$ A; $21.50 \min , 68 \%$ A; $23 \mathrm{~min}, 66 \% \mathrm{~A} ; 24 \mathrm{~min}, 65 \% \mathrm{~A} ; 25.5 \mathrm{~min}, 60 \%$ A; $27 \mathrm{~min}, 50 \% \mathrm{~A} ; 30 \mathrm{~min}, 0 \% \mathrm{~A} ; 35 \mathrm{~min}, 0 \%$ $\mathrm{A}$; and $37 \mathrm{~min}, 95 \% \mathrm{~A}$. Flow rate was $0.5 \mathrm{~mL} \mathrm{~min}^{-\mathrm{w}}$. 
Spectroscopic and Spectrometric Conditions

The UV spectra were recorded every $0.4 \mathrm{~s}$, with a resolution of $2 \mathrm{~nm}$, from 190 to $750 \mathrm{~nm}$ by DAD (Agilent Technologies, Santa Clara, CA, USA).

The MS system was equipped with a dual ESI (electrospray ionization) source and operated in negative mode as reported by Tafuri et al. [50]. All the parameters were controlled by the Agilent MassHunter Data Acquisition Software, version B.05.01. Mass spectra were recorded in the mass range 100-1600 m/z (3 scans per second). Hexakis $\left({ }^{1} \mathrm{H}_{1}{ }^{1} \mathrm{H}\right.$, ${ }^{3} \mathrm{H}$-tetrafluoropentoxy)-phosphazene $\left(\mathrm{C}_{18} \mathrm{H}_{18} \mathrm{O}_{6} \mathrm{~N}_{3} \mathrm{P}_{3} \mathrm{~F}_{24}\right.$ at $m / z$ 922.009798, $\left.2 \mu \mathrm{mol} \mathrm{L}{ }^{-9}\right)$ (Sigma-Aldrich, St. Louis, MO, USA), and purine $\left(\mathrm{C}_{5} \mathrm{H}_{4} \mathrm{~N}_{4}\right.$ at $m / z 121.050873,10 \mu \mathrm{mol} \mathrm{L}{ }^{-1}$ ) (Sigma-Aldrich, St. Louis, MO, USA) were injected in the source $\left(0.060 \mathrm{~mL} \mathrm{~min}{ }^{-\mathrm{e}}\right)$ to perform the lock mass correction in real-time. The capillary was set at $4000 \mathrm{~V}$, cone 1 (skimmer 1) at $45 \mathrm{~V}$, fragmentor at $180 \mathrm{~V}$. Gas temperature was $350^{\circ} \mathrm{C}$, and the nebulizer was at 45 psi. The injection volume was $5 \mu \mathrm{L}$. For each treatment, three biological samples were analyzed in triplicate.

Mass Profiler Professional (Agilent Technologies, MPP v 13.1.1, Santa Clara, CA, USA) was used for molecular feature normalization, alignment, compound identification, and statistical analysis. MPP normalization and alignment parameters were: minimum number of ions (2); abundance filter (>5000 counts); intercept ( $0.4 \mathrm{~min})$, alignment RT window, and slope $(0 \%)$; intercept ( $2 \mathrm{mDa})$, alignment mass window, and slope (20 ppm). Only masses occurring in two of three samples were accepted. Masses found in blank runs from filtered masses were used to remove background noise. The ion chromatogram (EIC) was extracted with $\pm 20 \mathrm{ppm}$ single ion expansion with MassHunter software v B.06.00 (Agilent Technologies, Santa Clara, CA, USA).

\subsubsection{Phenolics' Identification}

The phenolics were identified by Mass Hunter Qualitative Analysis Software version B.06.00 (Agilent Technologies, Santa Clara, CA, USA). Identification was achieved by comparison with in-house databases (comprising data from METLIN library) and with existing literature data. Empirical formulas, calculated by isotope model (common organic molecules, ppm limit $=10$, limit charge state to a maximum of 2 , and use ${ }^{+} \mathrm{H}$ or ${ }^{-} \mathrm{H}$, or sodium and potassium adducts) were given for unidentified compounds. Experimental retention time, monoisotopic mass, and UV max of standards confirmed the identification.

\subsubsection{Phenolics' Quantification}

The quantification of phenolics was performed by using oleuropein and luteolin commercial standards purchased from Sigma-Aldrich (Sigma-Aldrich, St. Louis, MO, USA) dissolved in methanol: water (50:50, $v / v)$ to make standard calibration curves (Table S1).

\subsection{Statistical Analysis}

Statistical analysis was performed by SPSS V24 statistic software (IBM Corporation, Armonk, NY, USA). One-way ANOVA analyzed the data of SPAD index. Significant differences among treatments were compared using Fisher's least significant difference (LSD) post hoc tests and S-N-K (Student-Newman-Keuls) (with 0.05 level of significance). The Student's $t$-test (with a 0.05 level of significance) determined significant differences.

\section{Results}

\subsection{Effect of Treatments on the Olive Trees Drupe's Weight}

In the first year of production, the average weight of the drupes for each treatment was evaluated. All treatments, except T. harzianum M10 and T. asperellum KV906, positively affected the drupes' average weight compared to the control (Table 1). 
Table 1. Effects of treatments with Trichoderma spp. strains T22, M10, GV41, TH1, KV906 or its metabolites 6-pentyl- $\alpha$-pyrone (6PP) and harzianic acid (HA) on average weights of the drupes collected from the experimental field. The control (CTRL) was not treated with biostimulants.

\begin{tabular}{cc}
\hline Treatment & Drupe's Average Weight (g) \\
\hline GV41 & $8.10^{\mathrm{b}}$ \\
M10 & $5.66^{\mathrm{a}}$ \\
T22 & $7.61^{\mathrm{b}}$ \\
TH1 & $6.63^{\mathrm{b}}$ \\
KV906 & $5.90^{\mathrm{a}}$ \\
6PP & $6.12^{\mathrm{b}}$ \\
HA & $9.40^{\mathrm{b}}$ \\
CTRL & $5.85^{\mathrm{a}}$ \\
\hline
\end{tabular}

Different letters within each column indicate significant differences $(p<0.05)$.

\subsection{Characterization of Olive Drupe Metabolome}

Thirteen phenolic compounds were identified based on total ion chromatogram (TIC), mass/UV-VIS, spectra, and literature data. Identification parameters (retention time, UV maximum absorption, experimental and calculated monoisotopic masses, molecular formula) are reported in Table 2.

Table 2. Phenolics' identification parameters.

\begin{tabular}{|c|c|c|c|c|c|}
\hline Compound & RT (min) & UV Max (nm) & Experimental Mass & Mass Theoretical & Formula \\
\hline \multicolumn{6}{|l|}{ Secoiridoids } \\
\hline Oleuropein aglycone & 10.90 & $235 ; 271$ & 378.1569 & 378.13 & $\mathrm{C}_{16} \mathrm{H}_{26} \mathrm{O}_{16}$ \\
\hline Oleuropein isomer a & 19.10 & $240 ; 280$ & 540.1840 & 540.18 & $\mathrm{C}_{25} \mathrm{H}_{32} \mathrm{O}_{13}$ \\
\hline Oleuropein isomer b & 20.10 & $235 ; 280$ & 540.1848 & 540.184 & $\mathrm{C}_{25} \mathrm{H}_{32} \mathrm{O}_{13}$ \\
\hline 2"-Methoxyoleuropein & 15.81 & $236 ; 280$ & 570.1942 & 570.19 & $\mathrm{C}_{26} \mathrm{H}_{34} \mathrm{O}_{14}$ \\
\hline Ligstroside & 20.52 & $230 ; 280$ & 524.1900 & 524.19 & $\mathrm{C}_{25} \mathrm{H}_{32} \mathrm{O}_{12}$ \\
\hline \multicolumn{6}{|l|}{ Flavonoids } \\
\hline Luteolin & 20.80 & $255 ; 286$ & 286.0488 & 286.05 & $\mathrm{C}_{15} \mathrm{H}_{35} \mathrm{O}_{14}$ \\
\hline Luteolin rutinoside & 11.90 & $248 ; 267$ & 594.1589 & 594.16 & $\mathrm{C}_{27} \mathrm{H}_{30} \mathrm{O}_{15}$ \\
\hline Luteolin di-glucoside & 12.25 & $248 ; 267 ; 335$ & 610.1537 & 610.15 & $\mathrm{C}_{27} \mathrm{H}_{30} \mathrm{O}_{16}$ \\
\hline Rutin & 14.60 & 253 & 610.1539 & 610.15 & $\mathrm{C}_{27} \mathrm{H}_{30} \mathrm{O}_{16}$ \\
\hline \multicolumn{6}{|l|}{ Simple phenols } \\
\hline Hydroxytyrosol-glucoside & 4.75 & $230 ; 280$ & 316.1160 & 316.12 & $\mathrm{C}_{14} \mathrm{H}_{20} \mathrm{O}_{8}$ \\
\hline Verbascoside & 14.55 & $234 ; 329$ & 624.2064 & 624.20 & $\mathrm{C}_{29} \mathrm{H}_{36} \mathrm{O}_{15}$ \\
\hline \multicolumn{6}{|l|}{ Oleosides } \\
\hline Oleoside methyl ester & 6.33 & 235 & 404.1321 & 404.13 & $\mathrm{C}_{17} \mathrm{H}_{24} \mathrm{O}_{11}$ \\
\hline Secologanoside & 7.45 & 234 & 390.1151 & 390.12 & $\mathrm{C}_{16} \mathrm{H}_{22} \mathrm{O}_{11}$ \\
\hline
\end{tabular}

\subsection{Untargeted Metabolomics Analyses of Phenolics in Olive Drupes}

Untargeted metabolomic analyses were carried out on the olives harvested from treated plants. There was a tendency for the number of down-regulated compounds to increase (Table 3). In general, a more significant number of compounds were observed whose abundance was lower when compared to the control. The metabolite 6PP and Trichoderma sp. strains GV41 and KV906 influenced the metabolic response in drupes more than the control.

Replicate samples were grouped and subjected to variance analysis (one-way ANOVA, $p<0.05)$ and to fold change (FC > 2.0), comparing metabolite abundances in treatments vs. water-treated plants (CTRL). Hierarchical cluster analysis and statistical analysis revealed 88 metabolites differentially accumulated among treatments that are depicted as hierarchical cluster in Figure 1. The metabolic profiling revealed that drupes from olive plants treated with the Trichoderma sp. strain M10, KV906, T22, and metabolite HA were 
grouped separately. TH1 determined no differences in terms of phenolic levels compared to the control.

Table 3. Number of metabolites whose production is higher (UP) or lower (DOWN) compared to the control (CTRL) in the drupes obtained from treated plants (Trichoderma spp. strains T22, M10, GV41, TH1, KV906 or its metabolites 6-pentyl- $\alpha$-pyrone (6PP) and harzianic acid (HA).

\begin{tabular}{ccc}
\hline Treatments & UP vs. CTRL & DOWN vs. CTRL \\
\hline GV41 & 21 & 30 \\
M10 & 16 & 44 \\
T22 & 10 & 38 \\
TH1 & 16 & 35 \\
KV906 & 21 & 44 \\
HA & 12 & 36 \\
6PP & 28 & 39 \\
\hline
\end{tabular}
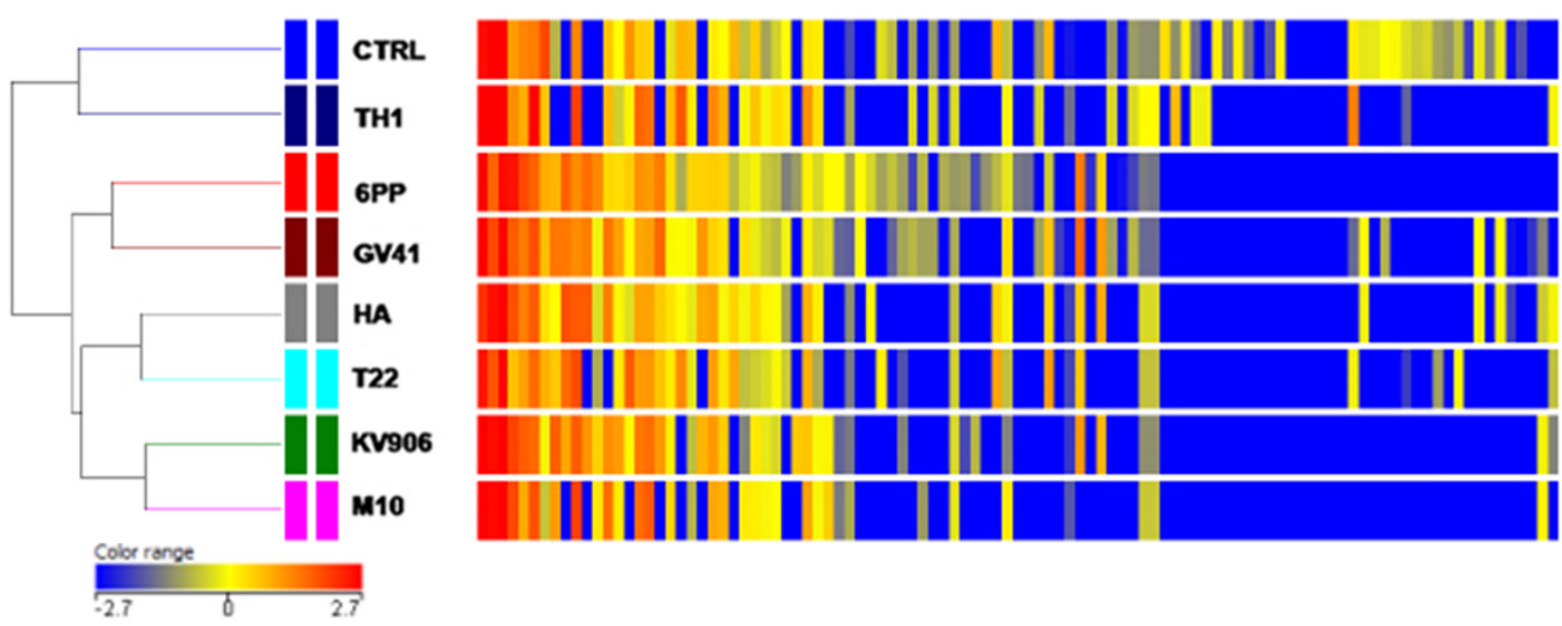

Figure 1. Hierarchical clustering heat map of differential metabolic profiles from olive drupe extracts. Samples are indicated by treatments with Trichoderma strains (TH1, GV41, T22, M10, and KV906) or secondary metabolites (HA and 6PP). Control was plants treated with water. Red color indicates higher phenolic abundance $(>0)$, blue colors lower $(<0)$, yellow a neutral change from the overall average abundance. Statistical significance was tested by one-way ANOVA $(p<0.05)$.

Successively, the variations in metabolite accumulation between increased (UP) or decreased (DOWN) compounds, as compared to the control, were analyzed for T22, M10 and HA.

A Venn diagram showed that 30 down-regulated compounds were in common among all treatments, while four metabolites were exclusively in the metabolome of T22-treated samples and four in those exposed to M10. No compound was found to be specific for HA treatment. Four metabolites were common to T22 and M10 treatments and six to M10 and HA. In contrast, no compounds were found to be common to T22 and HA treatments. Concerning the up-regulated compounds, five were common to all treatments, eight exclusive to M10, 1 to HA, and none for T22; one metabolite was common between treatments with T22 and M10, two between M10 and HA and four between HA and T22. (Figure 2).

Untargeted metabolomic analysis revealed the presence of several differentially accumulated metabolites in treated or non-treated drupes. Among these, 13 metabolites were putatively identified by comparison with an in-house database and standard compounds (Table 4). 


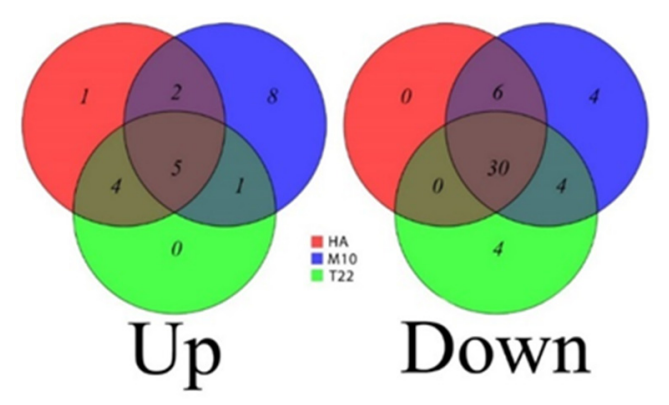

Figure 2. Venn diagrams of phenolic compounds whose abundance in the olive drupe metabolome is lower (DOWN) or higher (UP) compared to the control (CTRL). Samples treated with T22 are reported in green; with M10 in blue and with HA in red.

Table 4. Metabolites identified in the drupe extracts of olive trees subjected to field applications of biological treatments. Samples are indicated by treatments with Trichoderma strains (TH1, GV41, T22, M10, and KV906) or secondary metabolites (HA and 6PP). Identifications were confirmed by comparing results with known compounds in an in-house database/standards and selecting matching ( $\geq 95 \%)$.

\begin{tabular}{lccccccc}
\hline \multirow{2}{*}{ Compound } & \multicolumn{7}{c}{ Regulation against Control Group (CTRL) } \\
\cline { 2 - 7 } & M10 & KV906 & GV41 & TH1 & T22 & 6PP & HA \\
\hline Oleuropein aglycon & $\uparrow$ & $\uparrow$ & $\uparrow$ & $\uparrow$ & $\uparrow$ & $\uparrow$ & $\uparrow$ \\
Oleuropein isomer a & $\downarrow$ & $\downarrow$ & $\downarrow$ & $\downarrow$ & $\downarrow$ & $\downarrow$ & $\downarrow$ \\
Oleuropein isomer b & $\downarrow$ & $\downarrow$ & $\downarrow$ & $\downarrow$ & $\downarrow$ & $\downarrow$ & $\downarrow$ \\
2-Methoxyoleuropein & $\downarrow$ & $\downarrow$ & $\uparrow$ & $\uparrow$ & $\downarrow$ & $\downarrow$ & $\downarrow$ \\
Ligstroside & $\downarrow$ & $\downarrow$ & $\downarrow$ & $\downarrow$ & $\downarrow$ & $\downarrow$ & $\downarrow$ \\
Luteolin & $\uparrow$ & $\uparrow$ & $\uparrow$ & $\uparrow$ & $\downarrow$ & $\uparrow$ & $\uparrow$ \\
Luteolin rutinoside & $\uparrow$ & $\uparrow$ & $\uparrow$ & $\uparrow$ & $\uparrow$ & $\uparrow$ & $\uparrow$ \\
Luteolin di-glucoside & $\uparrow$ & $\uparrow$ & $\uparrow$ & $\uparrow$ & $\uparrow$ & $\uparrow$ & $\uparrow$ \\
Rutin & $\downarrow$ & $\downarrow$ & $\downarrow$ & $\downarrow$ & $\downarrow$ & $\uparrow$ & $\downarrow$ \\
Hydroxytyrosol & $\downarrow$ & $\downarrow$ & $\uparrow$ & $\uparrow$ & $\uparrow$ & $\downarrow$ & $\uparrow$ \\
glucoside & $\uparrow$ & $\uparrow$ & $\uparrow$ & $\uparrow$ & $\downarrow$ & $\uparrow$ & $\downarrow$ \\
Verbascoside & $\downarrow$ & $\downarrow$ & $\uparrow$ & $\uparrow$ & $\uparrow$ & $\downarrow$ & $\uparrow$ \\
Oleoside methyl ester & $\downarrow$ & $\downarrow$ & $\downarrow$ & $\uparrow$ & $\downarrow$ & $\downarrow$ & $\downarrow$ \\
Secologanoside & $\downarrow$ & $\downarrow$
\end{tabular}

$\uparrow$ Increased production of the metabolite in treated vs. control. $\downarrow$ Decreased production of the metabolite in treated vs. control.

\subsection{Targeted Metabolomics Analyzes of Phenolics in Olive Drupes}

Oleuropein (secoiridoid) and luteolin (flavonoid) concentrations were considered to evaluate the phenolics' level trends. Oleuropein content increased in the drupes of plants treated with 6PP, GV41, and T22 (Figure 3).

The secondary metabolite 6PP and the Trichoderma strains GV41, KV906, HA, and M10, increased the luteolin's level in drupes (Figure 4). 


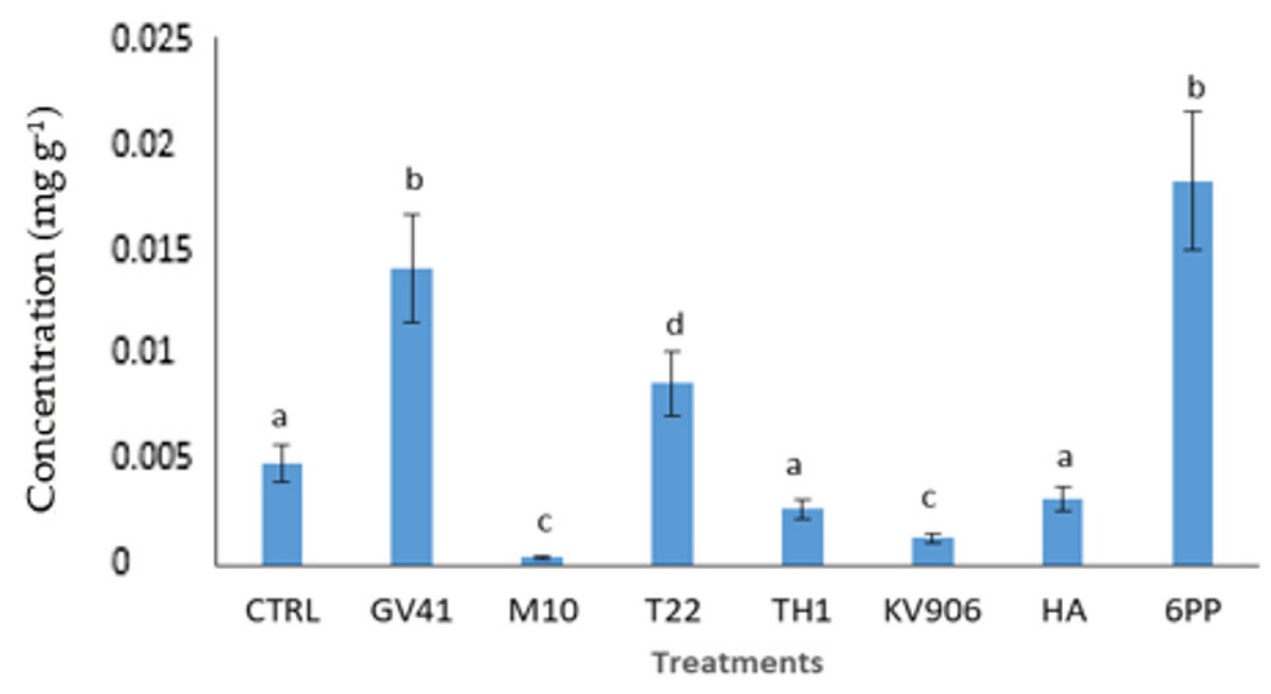

Figure 3. Oleuropein content in drupes. Samples are indicated by treatments with Trichoderma strains (TH1, GV41, T22, M10, and KV906) or secondary metabolites (HA and 6PP). Values are the means of three replicates \pm SE. Different letters indicate significant differences $(p<0.05)$.

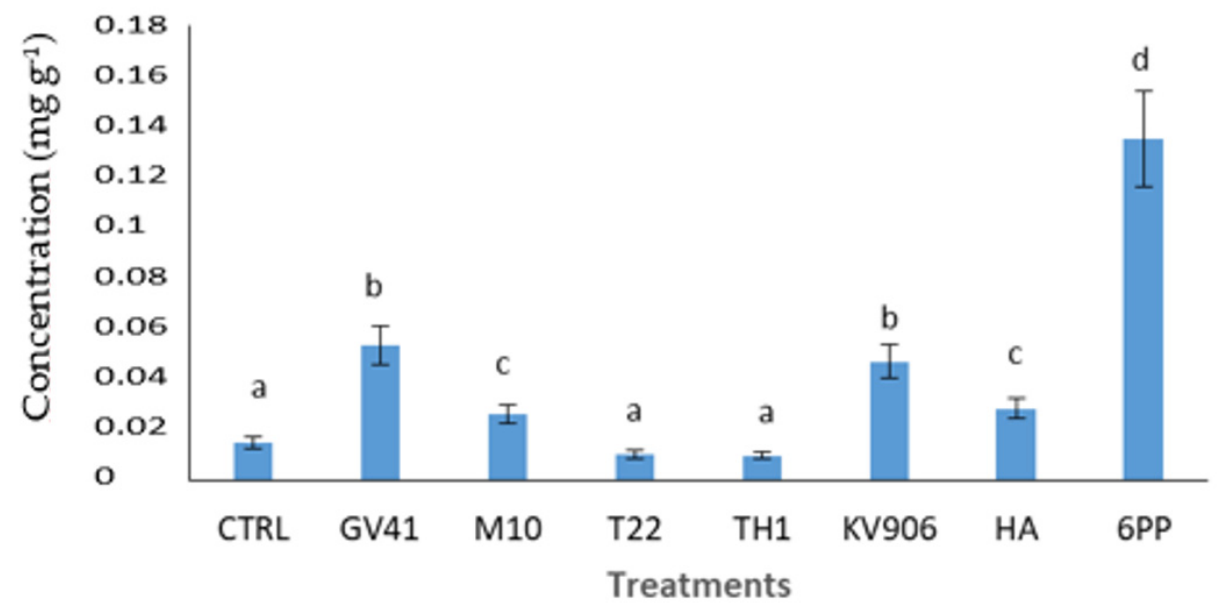

Figure 4. Luteolin content in drupes. Samples are indicated by treatments with Trichoderma strains (TH1, GV41, T22, M10, and KV906) or secondary metabolites (HA and 6PP). Values are the means of three replicates \pm SE. Different letters indicate significant differences $(p<0.05)$.

\section{Discussion}

Today, it is considered a priority to limit pesticides against phytopathogenic agents or replace them with products of biological origin. The use of mycoparasitic fungi, particularly those belonging to the genus Trichoderma, has met considerable success [11]. The world market of biopharmaceuticals proposes over 50 bioformulates containing Trichoderma strains as active ingredients [51]. The considerable achievement of Trichoderma fungi in agriculture is due to their suppression of pathogenic species, both terricolous and foliar, among the most harmful, such as those belonging to the genera Fusarium, Sclerotinia, Botrytis, and Pythium [52]. Microbial inocula to promote plant development and/or control phytopathogenic agents is still not very widespread in tree crops. Few studies evaluated the effect of beneficial microorganisms on the fitness of the olive tree and provided helpful information for the use of bioformulates in the open field. The present work aims to evaluate the effects of the field applications of Trichoderma spp. strains and some of their metabolites on young olive trees' drupes weight and nutraceutical content contained therein.

The olive is the most representative tree in Italy, with both historical and productive significance. There are three types of olives on the market: olive for oil production, olive for 
the table, and dual-use. Fruit size, oil content flesh, and weight/pit weight ratio determine the inclusion in the product classes. Olives for oil production have an average weight below 3, table-use have an average weight higher than 5, dual-use between 3 and 5 [53]. Extensive research has been conducted on multiple species to understand the mechanisms that control fruit size [54]. Environmental and genetic factors affect the fruits' growth potential [55]. In particular, the water volume and the type of irrigation used for cultivation are noteworthy [56]. Water deficit results in high reactive oxygen species (ROS) (e.g., hydrogen peroxide, hydroxyl radical superoxide anion, and singlet oxygen) [57]. ROS can damage DNA, lipids, and protein, thereby affecting plants' metabolism [58]. Plants react to ROS, making enzymes with different biological activities (e.g., catalase, ascorbate peroxidase, superoxide dismutase, monodehydroascorbate reductase, dehydroascorbate reductase, guaiacol peroxidase, and glutathione reductase) [59] and primary or secondary metabolites (e.g., polyols, soluble sugars, alkaloids, free amino acids, and phenols) [60]. In this work, all treatments (excluding M10 and KV906) enhanced drupe weight, probably due to Trichoderma strains' ability to induce root growth, preserve nutritional uptake, and interfere with phenolics' productions [61]. The diverse response to bio-treatments was probably linked to the different abilities of each strain and metabolite to interact with the plant's secondary defense mechanisms [15]. The variation in phenolics (variety and levels) was tested using targeted and untargeted metabolomics to evaluate the interaction of Trichoderma spp. and metabolites with the plant defense mechanism. Targeted metabolomics uses analytical techniques and suitable multivariate statistical analysis (MSA) tools to evaluate some metabolites simultaneously [62]. The untargeted approach determines unknown and known metabolic changes based on data-independent acquisition (DIA). DIA methods make complex fragmentation spectra. In downstream data analysis steps, fragment ions are matched with precursor ions based on mass and retention time [63].

In this study, an untargeted metabolomic approach was used to evaluate phenolic profiles for olive drupes. The analysis of chromatograms led to the putative identification of 13 differentially accumulated compounds among all treatments. Oleuropein (the main secoiridoid) and luteolin (the main flavonoid) concentration increased in treated samples compared to control. Metabolomic profiles of olive drupes following the application of M10, KV906, T22, and metabolite HA were grouped separately. This result may indicate that the olive plants have a similar response when inoculated with Trichoderma fungi and treated with their metabolites [51]. However, the identified differential metabolites were not always common to all treatments (Figure 1). The targeted metabolomics method estimated the effects of each biological treatment on the phenolic' levels in the olive's drupes. Four more representative phenolic classes (flavonoids, secoiridoids, simple phenols, and oleosides) were considered. Following the treatments, an increase in the oleuropein's content and a decrease in the oleuropein's precursors (11-methyl ester and ligstroside) concentrations were determined, demonstrating the ability of Trichoderma and its metabolites to interact with the enzyme $\beta$-glucosidase [64] responsible for this biotransformation (Figure 5) [65].

About flavonoids, an improvement of the flavone luteolin's level (except in olive drupes obtained from plants treated by T22) and a decrease in the flavonol rutin's concentration (except in olive drupes obtained from plants treated by 6PP) were observed in all tested samples (Table 4), indicating the ability of the treatments (except T22 and 6PP) to affect principally the flavone synthase activity rather than flavonol synthase (Figure 6).

Finally, the levels' variation of oleuropein and luteolin in olive drupes after the biotreatment was studied in detail. Oleuropein and luteolin were used as indicators of the secoiridoids and flavonoids variation, respectively. Oleuropein acts in Olea europaea as signaling molecule to protect the plant against UV-B radiation [67]. It has beneficial properties on human health, preventing cancer, cardiovascular diseases, inflammatory and oxidant damage [68]. Luteolin avoids oxidative and inflammatory processes with important implications for preventing neurodegenerative, cancer, and cardiovascular diseases and fortifying the immune system [69,70]. All Trichoderma spores and metabolites treatments affected the secoiridoid oleuropein and flavonoid luteolin levels (in some cases, 
they were less abundant in treated plants) and generally influenced the flavonoids more than secoiridoids production. The biological treatment (6PP, GV41, and T22) improved the oleuropein content, while the luteolin levels were higher after 6PP, GV41, M10, HA, and KV906 treatments confirming a different interaction capacity of the biotreatments with the enzymes involved in the two biosynthetic pathways.

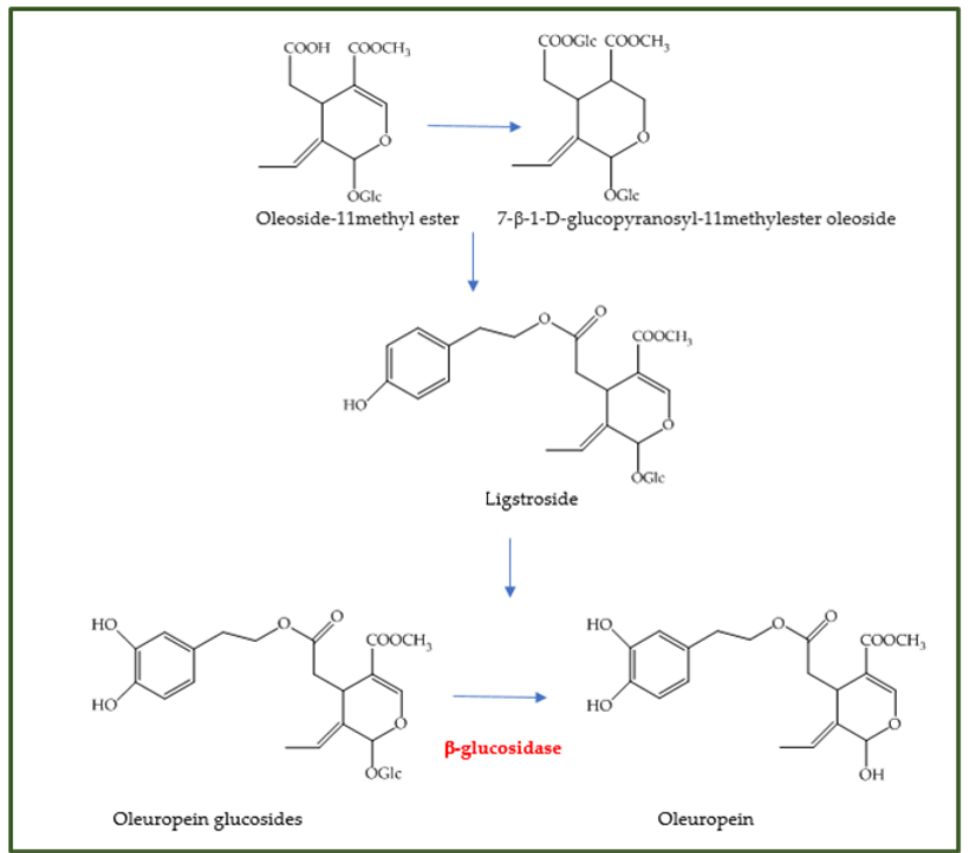

Figure 5. Oleuropein biosynthesis.

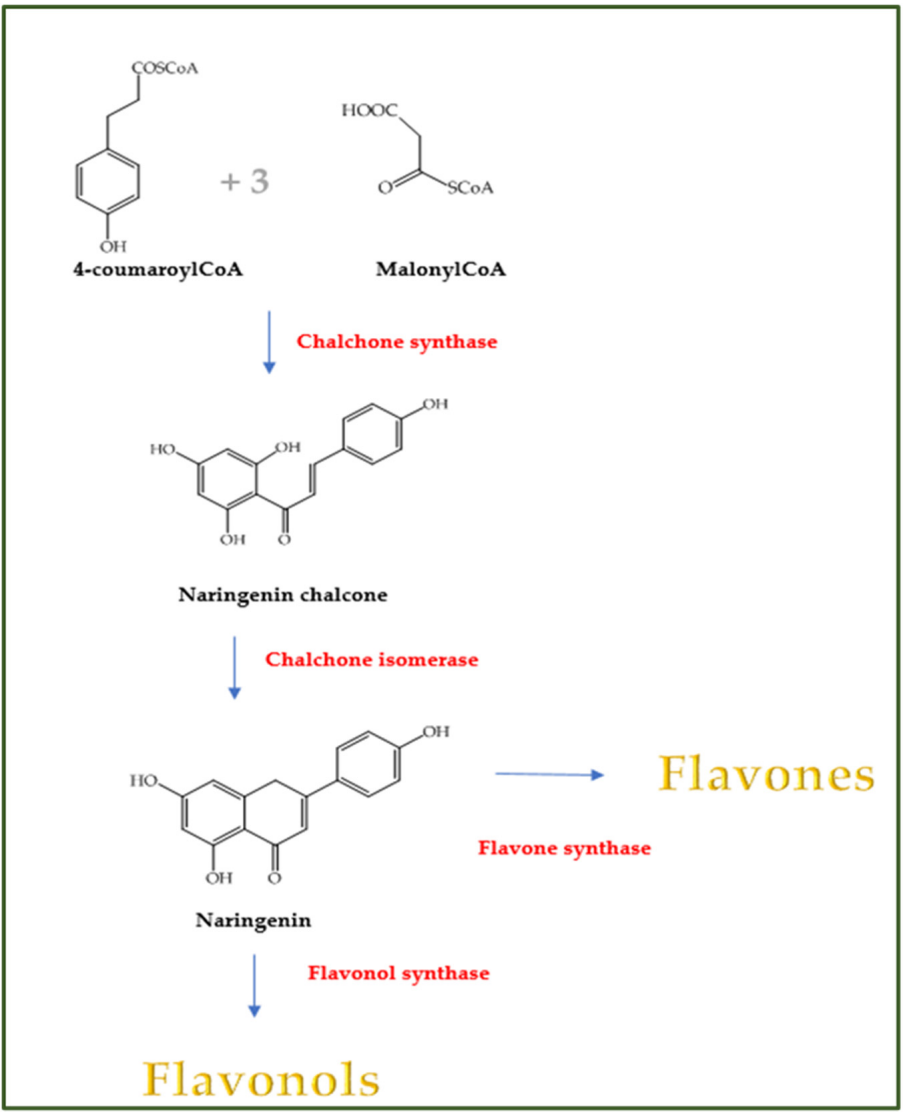

Figure 6. Flavonoid's biosynthesis [66]. 


\section{Conclusions}

Trichoderma strains and their bioactive metabolites used to cultivate the olive tree (O. europaea cv. Carolea) influence the weight of the drupes and the composition of phenolic compounds they contain, although in different ways depending on the strain or metabolite applied. All Trichoderma treatments influenced the production of flavonoids more than secoiridoids. The biological treatments' different abilities could depend on their selective aptitude to interact with the enzymes involved in flavonoid and secoiridoid production. Our results show that using the Trichoderma fungi and their metabolites represents a suitable alternative to synthetic fungicide since they are biocontrol agents and influence other desirable characteristics such as the size and nutraceutical properties of the olives. Furthermore, they suggest that in the future, the use of metabolites is preferable to that of living fungi as they give the same biological effects beneficial for cultivation and guarantee the nutraceutical properties of olives, avoiding some of the limitations related to the application of living microbes (difficulty in dosing concentrations to be applied on the plant and storage complications).

Supplementary Materials: The following are available online at https://www.mdpi.com/article/10 $.3390 /$ app11188710/s1, Table S1. Analytical parameters used to perform the calibration curves.

Author Contributions: Writing-original draft preparation, I.D. and F.V.; data curation, M.P. and A.S.; Formal analysis, A.S. and R.M.; Formal analysis and writing, F.V.; Investigation, A.S. and R.M.; project administration, F.V. All authors have read and agreed to the published version of the manuscript.

Funding: This work was supported by the following project: MIUR—PON [grant number Linfa 03PE_00026_1].

Institutional Review Board Statement: Not applicable.

Informed Consent Statement: Not applicable.

Data Availability Statement: Data is contained within the article or supplementary material.

Conflicts of Interest: The authors declare no conflict of interest.

\section{References}

1. Vossen, P. Olive Oil: History, Production, and Characteristics of the World's Classic Oils. HortScience 2007, 42, 1093-1100. [CrossRef]

2. Kaniewski, D.; Van Campo, E.; Boiy, T.; Terral, J.-F.; Khadari, B.; Besnard, G. Primary domestication and early uses of the emblematic olive tree: Palaeobotanical, historical and molecular evidence from the Middle East. Biol. Rev. Camb. Philos. Soc. 2012, 87, 885-899. [CrossRef]

3. Besnard, G.; Baradat, P.; Bervillé, A. Genetic relationships in the olive (Olea europaea L.) reflect multilocal selection of cultivars. Theor. Appl. Genet. 2001, 102, 251-258. [CrossRef]

4. Angiolillo, A.; Reale, S.; Pilla, F.; Baldoni, L. Molecular Analysis of Olive Cultivars in the Molise Region of Italy. Genet. Resour. Crop Evol. 2006, 53, 289-295. [CrossRef]

5. Marra, F.P.; Caruso, T.; Costa, F.; di Vaio, C.; Mafrica, R.; Marchese, A. Genetic relationships, structure and parentage simulation among the olive tree (Olea europaea L. subsp. europaea) cultivated in Southern Italy revealed by SSR markers. Tree Genet. Genomes 2013, 9, 961-973. [CrossRef]

6. Kapellakis, I.E.; Tsagarakis, K.P.; Crowther, J.C. Olive oil history, production and by-product management. Rev. Environ. Sci. Biotechnol. 2008, 7, 1-26. [CrossRef]

7. Mazzocchi, A.; Leone, L.; Agostoni, C.; Pali-Schöll, I. The Secrets of the Mediterranean Diet. Does [Only] Olive Oil Matter? Nutrients 2019, 11, 2941. [CrossRef] [PubMed]

8. Schwingshackl, L.; Morze, J.; Hoffmann, G. Mediterranean diet and health status: Active ingredients and pharmacological mechanisms. Br. J. Pharmacol. 2019, 177, 1241-1257. [CrossRef] [PubMed]

9. Dini, I.; Laneri, S. Spices, Condiments, Extra Virgin Olive Oil and Aromas as Not Only Flavorings, but Precious Allies for Our Wellbeing. Antioxidants 2021, 10, 868. [CrossRef]

10. Pedan, V.; Popp, M.; Rohn, S.; Nyfeler, M.; Bongartz, A. Characterization of Phenolic Compounds and Their Contribution to Sensory Properties of Olive Oil. Molecules 2019, 24, 2041. [CrossRef]

11. Dini, I.; Seccia, S.; Senatore, A.; Coppola, D.; Morelli, E. Development and Validation of an Analytical Method for Total Polyphenols Quantification in Extra Virgin Olive Oils. Food Anal. Methods 2020, 13, 457-464. [CrossRef] 
12. Dini, I.; Graziani, G.; Fedele, F.L.; Sicari, A.; Vinale, F.; Castaldo, L.; Ritieni, A. Effects of Trichoderma Biostimulation on the Phenolic Profile of Extra-Virgin Olive Oil and Olive Oil By-Products. Antioxidants 2020, 9, 284. [CrossRef] [PubMed]

13. Bendini, A.; Cerretani, L.; Carrasco-Pancorbo, A.; Gómez-Caravaca, A.M.; Segura-Carretero, A.; Fernández-Gutiérrez, A.; Lercker, G. Phenolic molecules in virgin olive oils: A survey of their sensory properties, health effects, antioxidant activity and analytical methods. An overview of the last decade. Molecules 2007, 12, 1679-1719. [CrossRef] [PubMed]

14. Dini, I.; Graziani, G.; Fedele, F.L.; Sicari, A.; Vinale, F.; Castaldo, L.; Ritieni, A. An environmentally friendly practice used in olive cultivation capable of increasing commercial interest in waste products from oil processing. Antioxidants 2020, 9, 466. [CrossRef] [PubMed]

15. Casas, R.; Estruch, R.; Sacanella, E. The Protective Effects of Extra Virgin Olive Oil on Immune-mediated Inflammatory Responses. Endocr. Metab. Immune Disord. Drug Targets 2018, 18, 23-35. [CrossRef] [PubMed]

16. Santangelo, C.; Vari, R.; Scazzocchio, B.; de Sanctis, P.; Giovannini, C.; D'Archivio, M.; Masella, R. Anti-inflammatory Activity of Extra Virgin Olive Oil Polyphenols: Which Role in the Prevention and Treatment of Immune-Mediated Inflammatory Diseases? Endocr. Metab. Immune Disord. Drug Targets 2018, 18, 36-50. [CrossRef]

17. EFSA Panel on Dietetic Products, Nutrition and Allergies (NDA). Scientific Opinion on the substantiation of a health claim related to polyphenols in olive and maintenance of normal blood HDL cholesterol concentrations (ID 1639, further assessment) pursuant to Article 13(1) of Regulation (EC) No 1924/2006. EFSA J. 2012, 10, 2848. [CrossRef]

18. Tetens, I.; EFSA Panel on Dietetic Products, Nutrition and Allergies (NDA). Scientific Opinion on the Substantiation of a Health Claim Related to Glucosamine and Maintenance of Lycopene, Proanthocyanidins, Vitamin C, Vitamin E, Selenium and Beta-Carotene and Contribution to Normal Collagen Formation (ID 1669) and Protection of the Skin from UV-Induced Damage (ID 1669) Pursuant to Article 13(1) of Regulation (EC) No 1924/2006; European Food Safety Authority (EFSA): Parma, Italy, 2011.

19. Stark, A.; Zecharia, M. Olive oil in the prevention of breast and colon carcinogenesis. In Olives and Olive Oil in Health and Disease Prevention; Academic Press: Cambridge, MA, USA, 2021; pp. 337-345.

20. Dini, I.; Laneri, S. The New Challenge of Green Cosmetics: Natural Food Ingredients for Cosmetic Formulations. Molecules 2021, 26, 3921. [CrossRef]

21. Dini, I.; Falanga, D.; di Lorenzo, R.; Tito, A.; Carotenuto, G.; Zappelli, C.; Grumetto, L.; Sacchi, A.; Laneri, S.; Apone, F. An Extract from Ficus carica Cell Cultures Works as an Anti-Stress Ingredient for the Skin. Antioxidants 2021, 10, 515. [CrossRef]

22. Dini, I. Spices and herbs as therapeutic foods. In Food Quality: Balancing Health and Disease; Holban, A.M., Grumezescu, A.M., Eds.; Academic Press: New York, NY, USA; Elservier: London, UK, 2018; pp. 433-469.

23. Fanelli, F.; Cozzi, G.; Raiola, A.; Dini, I.; Mulè, G.; Logrieco, A.F.; Ritieni, A. Raisins and Currants as Conventional Nutraceuticals in Italian Market: Natural Occurrence of Ochratoxin A. J. Food Sci. 2017, 82, 2306-2312. [CrossRef]

24. Dini, I.; Laneri, S. Nutricosmetics: A brief overview. Phytother. Res. 2019, 33, 3054-3063. [CrossRef]

25. Cavallo, P.; Dini, I.; Sepe, I.; Galasso, G.; Fedele, F.L.; Sicari, A.; Bolletti Censi, S.; Gaspari, A.; Ritieni, A.; Lorito, M.; et al. An innovative olive pâté with nutraceutical properties. Antioxidants 2020, 9, 581. [CrossRef] [PubMed]

26. Dini, I.; Izzo, L.; Graziani, G.; Ritieni, A. The Nutraceutical Properties of "Pizza Napoletana Marinara TSG" a Traditional Food Rich in Bioaccessible Antioxidants. Antioxidants 2021, 10, 495. [CrossRef]

27. Rahioui, B.; Aissam, S.; Messaouri, H.; Moukhli, A.; Khadari, B.; Ei, M.C. Role of phenolic metabolism in the defense of the olive-tree against leaf-spot disease caused by Spilocaea oleagina. Int. J. Agric. Biol. 2013, 15, 273-278.

28. Rahioui, B.; El-Aabidine, A.Z.; Baissac, Y.; El-Boustani, E.; Khadari, B.; Jay Allemand, C.; El-Modafar, C. Phenolic compounds of olive-tree leaves and their relationship with the resistance to the leaf-spot disease caused by Spilocaea oleagina. Am. Eurasian J. Agric. Environ. Sci. 2009, 5, 204-214.

29. Markakis, E.A.; Tjamos, S.E.; Antoniou, P.P.; Roussos, P.A.; Paplomatas, E.J.; Tjamos, E.C. Phenolic responses of resistant and susceptible olive cultivars induced by defoliating and nondefoliating Verticillium dahlia pathotypes. Plant Dis. 2010, 94, 1156-1162. [CrossRef] [PubMed]

30. Petridis, A.; Therios, I.; Samouris, G.; Tananaki, C. Salinity-induced changes in phenolic compounds in leaves and roots of four olive cultivars (Olea europaea L.) and their relationship to antioxidant activity. Environ. Exp. Bot. 2012, 79, 37-43. [CrossRef]

31. Cetinkaya, H.; Koc, M.; Kulak, M. Monitoring of mineral and polyphenol content in olive leaves under drought conditions: Application chemometric techniques. Ind. Crops Prod. 2016, 88, 78-84. [CrossRef]

32. Mechria, B.; Tekayaa, M.; Hammamia, M.; Chehabb, H. Root verbascoside and oleuropein are potential indicators of drought resistance in olive trees (Olea europaea L.). Plant Physiol. Biochem. 2019, 141, 407-414. [CrossRef]

33. Dini, I.; Graziani, G.; Gaspari, A.; Fedele, F.L.; Sicari, A.; Vinale, F.; Cavallo, P.; Lorito, M.; Ritieni, A. New strategies in the cultivation of olive trees and repercussions on the nutritional value of the extra virgin olive oil. Molecules 2020, 25, 2345. [CrossRef] [PubMed]

34. Dini, I.; Marra, R.; Cavallo, P.; Pironti, A.; Sepe, I.; Troisi, J.; Scala, G.; Lombari, P.; Vinale, F. Trichoderma Strains and Metabolites Selectively Increase the Production of Volatile Organic Compounds (VOCs) in Olive Trees. Metabolites 2021, 11, 213. [CrossRef] [PubMed]

35. Woo, S.L.; Ruocco, M.; Vinale, F.; Nigro, M.; Marra, R.; Lombardi, N.; Pascale, A.; Lanzuise, S.; Manganiello, G.; Lorito, M. Trichoderma-based products and their widespread use in agricolture. Open Mycol. J. 2014, 8, 71-126. [CrossRef]

36. Lorito, M.; Woo, S.L.; Harman, G.E.; Monte, E. Translational research on Trichoderma: From 'omics to the field. Annu. Rev. Phytopathol. 2010, 48, 395-417. [CrossRef] [PubMed] 
37. Hermosa, R.; Viterbo, A.; Chet, I.; Monte, E. Plant-beneficial effects of Trichoderma and of its genes. Microbiology 2012, 158, 17-25. [CrossRef]

38. Mona, S.A.; Hashem, A.; Abd Allah, E.F.; Alqarawi, A.A.; Soliman, D.W.K.; Wirth, S.; Egamberdieva, D. Increased resistance of drought by Trichoderma harzianum fungal treatment correlates with increased secondary metabolites and proline content. J. Integr. Agric. 2017, 16, 1751-1757. [CrossRef]

39. Mukherjee, P.K.; Horwitz, B.A.; Kenerley, C.M. Secondary metabolism in Trichoderma-A genomic perspective. Microbiology 2012, 158, 35-45. [CrossRef] [PubMed]

40. Khan, R.A.A.; Najeeb, S.; Hussain, S.; Xie, B.; Li, Y. Bioactive Secondary Metabolites from Trichoderma spp. against Phytopathogenic Fungi. Microorganisms 2020, 8, 817. [CrossRef]

41. Pascale, A.; Vinale, F.; Manganiello, G.; Nigro, M.; Lanzuise, S.; Ruocco, M.; Marra, R.; Lombardi, N.; Woo, S.L.; Lorito, M. Trichoderma and its secondary metabolites improve yield and quality of grapes. Crop Prot. 2017, 92, 176-181. [CrossRef]

42. Mastouri, F.; Bjorkman, T.; Harman, G.E. Trichoderma harzianum enhances antioxidant defense of tomato seedlings and resistance to water deficit. Mol. Plant Microbe Interact. 2012, 25, 1264-1271. [CrossRef]

43. Rouphael, Y.; Carillo, P.; Colla, G.; Fiorentino, N.; Sabatino, L.; El-Nakhel, C.; Giordano, M.; Pannico, A.; Cirillo, V.; Shabani, E.; et al. Appraisal of combined applications of Trichoderma virens and a biopolymer-based biostimulant on lettuce agronomical, physiological, and qualitative properties under variable regimes. Agronomy 2020, 10, 196. [CrossRef]

44. Stoclet, J.C.; Chataigneau, T.; Ndiaye, M.; Oak, M.H.; el Bedoui, J.; Chataigneau, M.; Shini-Kerth, V.B. Vascular protection by dietary polyphenols. Eur. J. Pharm. 2004, 500, 299-313. [CrossRef] [PubMed]

45. Ruzzolini, J.; Peppicelli, S.; Andreucci, E.; Bianchini, F.; Scardigli, A.; Romani, A.; la Marca, G.; Nediani, C.; Calorini, L. Oleuropein, the Main Polyphenol of Olea europaea Leaf Extract, Has an Anti-Cancer Effect on Human BRAF Melanoma Cells and Potentiates the Cytotoxicity of Current Chemotherapies. Nutrients 2018, 10, 1950. [CrossRef] [PubMed]

46. Marra, R.; Lombardi, N.; d'Errico, G.; Troisi, J.; Scala, G.; Vinale, F.; Woo, S.L.; Bonanomi, G.; Lorito, M. Application of Trichoderma strains and metabolites enhances soybean productivity and nutrient content. J. Agric. Food Chem. 2019, 67, 1814-1822. [CrossRef] [PubMed]

47. Vinale, F.; Nicoletti, R.; Lacatena, F.; Marra, R.; Sacco, A.; Lombardi, N.; d’Errico, G.; Digilio, M.C.; Lorito, M.; Woo, S.L. Secondary metabolites from the endophytic fungus Talaromyces pinophilus. Nat. Prod. Res. 2017, 31, 1778-1785. [CrossRef]

48. Vinale, F.; Flematti, G.; Sivasithamparam, K.; Lorito, M.; Marra, R.; Skelton, B.W.; Ghisalberti, E.L. Harzianic acid, an antifungal and plant growth promoting metabolite from Trichoderma harzianum. J. Nat. Prod. 2009, 72, 2032-2035. [CrossRef]

49. Talhaoui, N.; Gómez-Caravaca, A.M.; León, L.; de la Rosa, R.; Segura-Carretero, A.; Fernández-Gutiérrez, A. Determination of phenolic compounds of 'Sikitita' olive leaves by HPLC-DAD-TOF-MS. Comparison with its parents' Arbequina' and 'Picual' olive leaves. LWT-Food Sci. Technol. 2014, 58, 28-34. [CrossRef]

50. Tafuri, S.; Cocchia, N.; Carotenuto, D.; Vassetti, A.; Staropoli, A.; Mastellone, V.; Peretti, V.; Ciotola, F.; Albarella, S.; del Prete, C.; et al. Chemical Analysis of Lepidium meyenii (Maca) and Its Effects on Redox Status and on Reproductive Biology in Stallions. Molecules 2019, 24, 1981. [CrossRef]

51. Marra, R.; Coppola, M.; Pironti, A.; Grasso, F.; Lombardi, N.; d’Errico, G.; Sicari, A.; Bolletti Censi, S.; Woo, S.L.; Rao, R.; et al. The Application of Trichoderma Strains or Metabolites Alters the Olive Leaf Metabolome and the Expression of Defense-Related Genes. J. Fungi 2020, 6, 369. [CrossRef]

52. Patkowska, E.; Mielniczuk, E.; Jamiołkowska, A.; Skwaryło-Bednarz, B.; BłaŻewicz-Woźniak, M. The Influence of Trichoderma harzianum Rifai T-22 and Other Biostimulants on Rhizosphere Beneficial Microorganisms of Carrot. Agronomy 2020, $10,1637$. [CrossRef]

53. Giuffrè, A.M. Biometric evaluation of twelve olive cultivars under rainfed conditions in the region of Calabria, South Italy. Emir. J. Food Agric. 2017, 29, 696. [CrossRef]

54. Rosati, A.; Zipanćič, M.; Caporali, S.; Padula, G. Fruit weight is related to ovary weight in olive (Olea europaea L.). Sci. Hortic. 2009, 122, 399-403. [CrossRef]

55. Hannachi, H.; Breton, C.; Msallem, M.; El-Hadj, S.B.; El-Gazzah, M.; Bervillé, A. Differences between native and introduced olive cultivars as revealed by morphology of drupes, oil composition and SSR polymorphisms: A case study in Tunisia. Sci. Hortic. 2008, 116, 280-290. [CrossRef]

56. Smirnoff, N. The role of active oxygen in the response of plants to water deficit and desiccation. New Phytol. 1993, 125, 27-58. [CrossRef]

57. Kaushik, D.; Roychoudhury, A. Reactive oxygen species (ROS) and response of antioxidants as ROS-scavengers during environmental stress in plants. Front. Environ. Sci. 2014, 2, 53.

58. Hasanuzzaman, M.; Bhuyan, M.H.M.B.; Parvin, K.; Bhuiyan, T.F.; Anee, T.I.; Nahar, K.; Hossen, M.S.; Zulfiqar, F.; Alam, M.M.; Fujita, M. Regulation of ROS Metabolism in Plants under Environmental Stress: A Review of Recent Experimental Evidence. Int. J. Mol. Sci. 2020, 21, 8695. [CrossRef]

59. Fang, Y.; Xiong, L. General mechanisms of drought response and their application in drought resistance improvement in plants. Cell. Mol. Life Sci. 2015, 72, 673-689. [CrossRef]

60. Ahmad, P.; Hashem, A.; Abd_Allah, E.F.; Alqarawi, A.A.; John, R.; Egamberdieva, D.; Gucel, S. Role of Trichoderma harzianum in mitigating $\mathrm{NaCl}$ stress in Indian mustard (Brassica juncea L.) through antioxidative defense system. Front. Plant Sci. 2015, 6, 868. [CrossRef] [PubMed] 
61. Schrimpe-Rutledge, A.C.; Codreanu, S.G.; Sherrod, S.D.; McLean, J.A. Untargeted Metabolomics Strategies-Challenges and Emerging Directions. J. Am. Soc. Mass Spectrom. 2016, 27, 1897-1905. [CrossRef]

62. Mayo-Prieto, S.; Marra, R.; Vinale, F.; Rodríguez-González, Á.; Woo, S.L.; Lorito, M.; Casquero, P.A. Effect of Trichoderma velutinum and Rhizoctonia solani on the Metabolome of Bean Plants (Phaseolus vulgaris L.). Int. J. Mol. Sci. 2019, 20, 549. [CrossRef]

63. Gutierrez-Rosales, F.; Romero, M.P.; Casanovas, M.; Motilva, M.J.; Mínguez-Mosquera, M.I. Metabolites involved in oleuropein accumulation and degradation in fruits of Olea europaea L.: Hojiblanca and Arbequina varieties. J. Agric. Food Chem. 2010, 58, 12924-12933. [CrossRef] [PubMed]

64. Damtoft, S.; Franzyk, H.; Jensen, S.R. Biosynthesis of secoiricoid glucosides in Oleaceae. Phytochemistry 1993, 34, 1291-1299. [CrossRef]

65. Damtoft, S.; Franzyk, H.; Jensen, S.R. Biosynthesis of iridoids in Syringa and Fraxinus: Secoiridoid precursors. Phytochemistry 1995, 40, 773-784. [CrossRef]

66. Morita, Y.; Hoshino, A. Recent advances in flower color variation and patterning of Japanese morning glory and petunia. Breed. Sci. 2018, 68, 128-138. [CrossRef]

67. Dias, M.C.; Pinto, D.C.G.A.; Freitas, H.; Santos, C.; Silva, A.M.S. The antioxidant system in Olea europaea to enhanced UV-B radiation also depends on flavonoids and secoiridoids. Phytochemistry 2020, 170, 112199. [CrossRef] [PubMed]

68. Omar, S.H. Oleuropein in olive and its pharmacological effects. Sci. Pharm. 2010, 78, 133-154. [CrossRef]

69. Montesano, D.; Rocchetti, G.; Cossignani, L.; Senizza, B.; Pollini, L.; Lucini, L.; Blasi, F. Untargeted Metabolomics to Evaluate the Stability of Extra-Virgin Olive Oil with Added Lycium barbarum Carotenoids during Storage. Foods 2019, 8, 179. [CrossRef] [PubMed]

70. Xu, H.; Linn, B.S.; Zhang, Y.; Ren, J. A review on the antioxidative and prooxidative properties of luteolin. React. Oxyg. Species 2019, 7, 136-147. [CrossRef] 